\title{
ENSINO DE QUÍMICA ORGÂNICA COM O USO DOS OBJETOS DE APRENDIZAGEM ATOMLIG E SIMULADOR CONSTRUTOR DE MOLÉCULAS
}

\author{
Alessandro Félix Pascoin ${ }^{1}$ \\ José Wilson Pires Carvalho ${ }^{2}$ \\ Daise Lago Pereira Souto ${ }^{3}$
}

\begin{abstract}
Resumo: $\mathrm{O}$ presente estudo teve como objetivo avaliar as potencialidades e limitaçóes dos recursos "modelos moleculares com tecnologia digital" e kit molecular Atomlig 77 Educaçâo em atividades de ensino abordando o conteúdo de cadeias carbônicas. A presente pesquisa possui caráter qualitativo e foi realizada com um grupo de alunos do terceiro ano do ensino médio de uma escola estadual de Mato Grosso. Trata-se de uma pesquisa qualitativa de caráter participante e para análise dos dados foi usado o método indutivo interpretativo. Os dados analisados sugerem que os diferentes modelos representativos de estruturas moleculares, seja no campo virtual ou por manuseio de modelos moleculares Atomlig 77 Educaçâo, mostraram-se complementares, visto que podem motivar os alunos e aprimoram as representaçôes de cadeias carbônicas. Além disso, as práticas pedagógicas diversificadas também contribuíram para motivar e aproximar os alunos dos conceitos químicos de forma interativa, aprimorando as representaçóes de cadeias carbônicas. Assim, por meio desse estudo, identificou-se como potencialidade a possibilidade do desenvolvimento de atividades em diferentes espaços, despertando o interesse por parte dos alunos. Por outro lado, também houve limitaçóes nos aspectos conceituais ligados aos objetos moleculares manuseáveis, bem como no caso dos objetos moleculares virtuais que requerem aprimoramentos. Por fim, o uso dos diferentes objetos mostrou-se positivo e importante para despertar o interesse dos alunos, podendo ser um importante recurso nos processos de ensino e aprendizagem de química.
\end{abstract}

Palavras-chave: Tecnologias Digitais. Objetos moleculares. Prática pedagógica.

1 Graduação em Química, Mestrando do Programa de Pós-Graduação Stricto Senso em Ensino de Ciências e Matemática da Universidade do Estado de Mato Grosso- PPGECM - UNEMAT/ Barra do Bugres/MT, Brasil.

2 Licenciatura em Química, Mestre em Físico-química e Doutor em Ciências, Professor do PósGraduação Stricto Senso em Ensino de Ciências e Matemática PPGECM - UNEMAT/Barra do Bugres/MT, Brasil.

3 Graduação em Matemática, Mestre em Modelagem Matemática e Doutora em Educação Matemática, Professora do Pós-Graduação Stricto Senso em Ensino de Ciências e Matemática. PPGECM - UNEMAT/Barra do Bugres/MT, Brasil. 


\title{
TEACHING OF ORGANIC CHEMISTRY BY USING ATOMLIG LEARNING OBJECTS AND MOLECULE CONSTRUCTOR SIMULATOR
}

\begin{abstract}
The present study aimed to evaluate the potentialities and limitations of the "molecular models with digital technology" and molecular kit Atomlig 77 Education in teaching activities addressing the content of carbon chains. This research is qualitative and it was conducted with a group of third year high school students from a state school in Mato Grosso. It is a qualitative research of participant character and for the analysis of the data the inductive interpretative method was used. The data analyzed suggest that the different models representing molecular structures, either in the virtual field or by handling molecular models Atomlig 77 Education, were complementary, since they can motivate students and improve the representations of carbon chains. In addition, diversified pedagogical practices have also contributed to motivate and bring students closer to chemical concepts interactively, improving the representations of carbon chains. Thus, through this study, it was identified as potentiality the possibility of developing activities in different spaces, arousing the interest of the students. On the other hand, there were also limitations in the conceptual aspects linked to the manipulable molecular objects, as well as in the case of virtual molecular objects that require improvements. Finally, the use of different objects proved to be positive and important to arouse students' interest, and may be an important resource in the teaching and learning processes of chemistry.
\end{abstract}

Keywords: Digital Technologies. Molecular objects. Pedagogical practice.

\section{INTRODUÇÃO}

Os avanços tecnológicos têm apresentados impactos no contexto educacional, e dentre eles destacam-se o uso das tecnologias digitais da informação e comunicação (TDIC) nos processos de ensino e de aprendizagem, alterando o espaço e tempo no decorrer desses processos. $\mathrm{O}$ ambiente de ensino tem sido marcado por uma profunda e acelerada mutação, mediado pela maciça difusão dos meios comunicacionais, ancorados invariavelmente em TDICs (PAULLETI; CATELLI, 2012; TAROUCO et al., 2014; MACIEL; ANJOS, 2013).

Nessa conjuntura as TDICs são fundamentais na formação dos alunos, pois, além de permitir maior liberdade social, proporciona mais comodidade (MARTINS, 2003). Ao inserir as TDICs no ensino de química, além de novos espaços de aprendizagem "[...] cria-se uma relação do aluno com o objeto de estudo mediante a interação, e é nessa relação do aluno com o objeto de estudo que pode surgir o aprendizado" (PAULLETI; CATELLI, 2012, p. 04).

As TDICs estão presentes na escola, direta ou indiretamente cabendo aos professores se aterem as novas exigências e inclinações que suscitam o exercício da profissão docente (KENSKI, 2012). Dentre essas exigências as mídias audiovisuais compreendem parte do acervo que integram as possibilidades pedagógicas que emergem das TDICs. Segundo Leão e Souto (2015, p.02), "estes recursos midiáticos e tecnológicos têm grande potencial educativo, pois permitem ao homem ultrapassar os limites impostos pelo espaço-tempo". Mesmo com o potencial do 
uso de tecnologias digitais no ensino, questões vêm se colocando de maneira cada vez mais consistente: como incorporar as TDICs na prática pedagógica a fim de ampliar a participação do aluno e potencializar o acesso à informação?

Diante de incertezas quanto as contribuições das tecnologias digitais no contexto educacional, em particular no ensino de química, conjecturam-se a necessidade de investigar essa temática. A esse respeito credita-se, que discutir sobre simulações virtuais junto a outras modalidades representacionais, no campo da experimentação como o Atomlig 77 Educação, pode ser uma forma de despertar o interesse dos alunos pela temática.

Assim, a pesquisa que deu origem a este artigo teve como objetivo avaliar as potencialidades e limitações dos recursos "modelos moleculares com tecnologia digital" e kit molecular Atomlig 77 Educação em atividades de ensino abordando o conteúdo de cadeias carbônicas.

Reconhecendo-se as dificuldades que os alunos apresentam em compreender conceitos relacionados a cadeias carbônicas, como descrevem Pozo e Crespo (2019) e Giordan (2008), optou-se por desenvolver essa pesquisa em uma escola estadual da rede pública com alunos que cursam o terceiro ano do ensino médio. Assim, apoiou-se na pesquisa participante com uma abordagem qualitativa. Nas seções seguintes, são apresentados os embasamentos teóricos que sustentam as discussões, bem como a organização, apresentação e discussão dos dados.

\section{Modelos moleculares para o ensino de Química e Ambientes virtuais}

O ensino de química pode tornar-se mais interativo, dinâmico e personalizado com o uso de Ambientes Virtuais de Aprendizagem (MELLO, 2009). Contudo, é recomendável que esses espaços virtuais sejam mediados por TDICs para atender as demandas educacionais.

Anjos (2013, p.42) considera Ambientes Virtuais de Aprendizagem (AVA), como sendo "[...] espaço de abstração ${ }^{4}$ tridimensional ou bidimensional, que servirá como repositórios de objetos virtuais com atributos a eles associados, baseados ou não em modelos reais". Segundo Kenski (2009, p.94) os AVA surgem como "[...] uma outra realidade, que pode existir paralelamente aos ambientes vivencias concretos (aqueles que estamos fisicamente presentes) e se abre para criação de espaços educacionais radicalmente diferentes". Nesse contexto, o papel dos AVA se amplia constantemente com diversas possibilidades didáticas, recursos de mídias e componentes mediadores nos processos de ensino e de aprendizagem. Para Souto (2014) [...] "o processo de mediação do ambiente virtual entre o sujeito e o objeto da atividade é condicionado pelas possibilidades que o próprio ambiente oferece".

4 O termo abstração, nesse contexto, refere-se à capacidade de desenvolver as ideias mentalmente, antes de passá-las a um plano material. No ensino de química, utilizado para expor conceitos, muitas vezes relacionados a naturezas química submicroscópicas (GIORDAN, 2013). 
Dentre os recursos pedagógicos que emergem de ambientes virtuais, estão os objetos moleculares que por meio de simulação oferecem aos alunos uma abordagem personalizada na edição e construção de moléculas orgânicas (GIORDAN, 2008). A interatividade oferecida pelos objetos moleculares está entre as contribuições desse recurso, que além de ser gratuito, acessível se manifesta, colaborador da qualidade e do êxito nos processos de ensino e de aprendizagem da química.

Tem sido discutido muitos aspectos conceituais da química, que são representados por modelos, e com isso, propriedades da matéria em nível atômicomoleculares que não podem ser visualizadas diretamente são representadas a partir de modelos moleculares relativamente simples (LIMA, 2014), (GIORDAN, 2018), (SILVA; SOUZA; FILHO, 2017). É nesse contexto, que as estruturas submicroscópicas, atômico-moleculares (partículas), seus movimentos, interações, requerem interpretações mais elaboradas, abstração, e que por meio de objetos moleculares, podem ser visualizadas e simuladas virtualmente ou por materiais alternativos de aprendizagem que também podem ser explorados. A esse respeito, Giordan (2013) considera objetos moleculares como sendo simuladores de partículas submicroscópicas em que o meio de veiculação pode ser representado por papel, bolas de isopor ou plástico, chegando ao computador com simulações e animações digitais.

Para Giordan e Góis (2005), os objetos moleculares virtuais, apresentam diversas possibilidades, dentre elas estão à disposição de múltiplas representações coordenadas e tridimensionalmente projetadas, variados tipos de manipulação destes objetos, como translação, rotação, aumento ou redução de tamanho.

Trazendo esses recursos para o âmbito pedagógico, observa-se que além de ser mais uma possibilidade didática para o ensino de conceito químico, ampliamse horizontes e multiplica-se as possibilidades educativas, visto que os objetos moleculares estão disponíveis gratuitamente em diversos sites (repositórios) e softwares. Partindo deste pressuposto Gabini e Diniz (2007), ressaltam que cada recurso de tecnologia digital a ser utilizado propõe contemplar as expectativas dos envolvidos nos processos de ensino e de aprendizagem e atender ao planejamento de modo específico, para que assim o aluno aprenda e não apenas acumule informação (GABINI; DINIZ, 2007).

Assim, de modo específico os softwares de edição e construção de objetos moleculares para simulação no contexto educacional, além de proporcionar possibilidades aos alunos na construção de modelos, ampliam a concepção conceitual dos objetos de estudos por meio da representação tridimensional de espécies químicas (RIBEIRO; GRECA, 2012).

Para tanto, Tarouco (2014) pontua que os recursos pedagógicos (softwares educativos, objetos moleculares), deverão estar integrados ao plano de ensino para que possam cumprir seu papel em sala de aula. Nessa conjuntura, outro ponto importante que vale a pena ressaltar e contempla a pesquisa, são as relações a serem estabelecidas entre professor e aluno no desenvolvimento das atividades propostas, 
o docente como mediador da aprendizagem e o aluno independente na construção de seu conhecimento.

\section{Representaçóes moleculares para o estudo da química orgânica}

Os desafios recorrentes no ensino da química impulsionam pesquisas que podem trazer respostas no tocante a reestruturação das práticas pedagógicas para esta ciência, pois segundo Pozo e Crespo (2009, p.144), "frente a uma visão centrada nos fatos e nas propriedades observáveis das substâncias, torna-se necessário compreender a matéria como um complexo sistema de partículas em contínua interação".

No que se refere a realidade observável da matéria, em especial no ensino de Química Orgânica, as dificuldades tendem a aumentar, pois nos estudos de conceitos que abordam a estrutura espacial das moléculas, a ciência opera com modelos integralmente abstratos (GIORDAN, 2013). As "partículas e transformações são representadas por meio de símbolos, fórmulas e equações químicas, bem como, expressões algébricas, tratando $\square$ se, portanto, de uma materialização semiótica da realidade" (GIORDAN; GÓIS, 2004, p.03). Nesse contexto, em muitas transformações químicas, os átomos e moléculas quando representados visualmente em situações estruturadas de ensino ampliam contribuições para o aprendizado de conceitos teóricos da química (OLIVEIRA; SOUTO; CARVALHO, 2016).

Nesta perspectiva, há um consenso teórico que átomos do elemento químico carbono ao formar estruturas chamadas cadeias carbônicas cujas representações das formas estruturais ou espaciais admitem uma dimensão distante da realidade onde ocorrem fenômenos que abrange o movimento e a interação dos átomos e moléculas. Diante do exposto, além do formato de representação, o fator determinante e merecedor de atenção passa a ser a estruturação de atividades, pelas quais as abordagens teóricas carecem de informações representacionais das realidades macroscópicas e submicroscópicas/atômica-molecular.

Nesse sentido, o cenário atual tem exigido pesquisas, formações e o aperfeiçoamento de estratégias didáticas que utiliza modelos atômico-moleculares para o fortalecimento e no desenvolvimento de atividades educacionais. Segundo Giordan (2013), para à estratégia de ensino e o alcance de significados na fronteira destas realidades é preciso empregar a forma de representação mais adequada à situação de ensino.

Os modelos moleculares são recursos alternativos que podem colaborar com o desenvolvimento educacional, apresentando-se como material didáticopedagógico acessível aos professores e alunos, podendo ser confeccionados com materiais encontrados no cotidiano e de baixo custo (SILVA; SOUZA; FILHO, 2017). No caso particular do ensino das cadeias carbônicas os modelos moleculares "integraram uma estrutura funcional que possibilita visualizar e explicar o comportamento das mesmas, analisando seus conceitos e sua geometria" (AlMEIDA; SILVA; CARVALHO, 2010, p. 7). 
Nesse caso, recursos pedagógicos alternativos alinhados e próximos ao aspecto interativo e lúdico, propõe reorientar o ensino da química, compreendendo parte da busca pela superação dos desafios no âmbito das representações de dimensões geométricas moleculares. Nessa circunstância, manusear os modelos moleculares garante a interação física e motora. De acordo com Soares (2004), quando a pessoa opera e manuseia um brinquedo, um simulador ou participa de uma atividade lúdica, admite-se uma correspondência intelectual.

Tendo em vista as possibilidades apresentadas para o ensino e a aprendizagem da química, a ludicidade integra parte dessa conjuntura de atividades pedagógicas, visto que, as atividades lúdicas são influentes na aprendizagem quando presentes em práticas escolares, em atividades interativas, jogos, recursos tecnológicos, modelos representativos entre outras estratégias de ensino que possibilitam a aproximação dos alunos do conhecimento científico (KIEL; CRISOSTIMO, 2017).

Em síntese, com base nas ideias expostas, foram organizadas atividades para que houvesse construção e representação virtual e manuseio de objetos moleculares manuseáveis do tipo bola-vareta (Atomlig 77 Educaşão). E assim, com intuito de ajustar a proposta da pesquisa e romper paradigmas no contexto do ensino da química, a fim de apresentar possibilidades e conhecer as limitações desses objetos moleculares.

\section{PROCEDIMENTOS METODOLÓGICOS}

Procurando alcançar os objetivos propostos, optou-se por desenvolver a metodologia de pesquisa participante com uma abordagem qualitativa. Segundo Oliveira (2016), a pesquisa participante exige um compromisso com a população em que se realiza o estudo. Oliveira (2016) ressalta também que nessas pesquisas é de fundamental importância o envolvimento dos pesquisadores nos grupos em que se realiza o processo de pesquisar. Nesse sentido, a investigação contém atributos desse método de pesquisa, ao reunir o compromisso dos pesquisadores com a população pesquisada buscando minimizar eventuais dificuldades no contexto educacional de modo participativo.

Para produção dos dados foram utilizados questionário com questões abertas e fechadas, observação participante referentes as ações desenvolvidas pelos alunos ao longo das atividades propostas, registrada em notas de campo. Com base na proposta mencionada, utilizou-se o método indutivo interpretativo para análise dos dados, que "compreende a observação e a experimentação dos fenômenos estudados" (SANTOS, 2016, p. 50). Conforme estabelecido nos objetivos da pesquisa, estruturou-se as atividades e conteúdos abordados de acordo com a fase em que cursavam os alunos participantes. Em relação a atividade proposta, realizouse a construção de cadeias carbônicas utilizando os objetos moleculares Atomlig 77 Educação (esfera manuseável), e o Software Construa uma molécula disponível no portal PhET - Interative Simulation.

Os sujeitos da pesquisa, foram alunos que cursavam o terceiro ano do ensino médio em uma escola pública da rede estadual de Educação no interior do estado 
de Mato Grosso, no município de Araputanga. Inicialmente, foram disponibilizados seis diferentes desafios sobre estruturas moleculares aos participantes, com informações (configuração estrutural das moléculas) para cada atividade. Cabendo aos alunos, diante das informações apresentadas, montarem as cadeias carbônicas solicitadas no campo virtual e com os modelos moleculares manuseáveis com base nas informações contidas no material disponibilizado pelos pesquisadores.

Ao final das atividades os participantes foram convidados a responderem o questionário na perspectiva que apontassem para dimensões que estavam sendo investigadas. A fim de preservar suas identidades, atribuímos para cada aluno participante os mencionados aqui a designação da letra "A", seguida de um número: "A1", "A2", "A3" e assim por diante.

Assumindo a existência das dificuldades dos alunos em compreender o nível tridimensional molecular, que integram os aspectos do conhecimento químico, apresenta-se nas seções a seguir como as atividades sobre cadeias carbônicas se constituíram, com a utilização de dois objetos moleculares que buscassem representar as especificidades do nível atômico-molecular desta ciência.

\section{Recursos didáticos selecionados utilizados nas atividades de ensino.}

O repositório PhET Interative Simulation da Universidade de Colorado Boulder disponibiliza de forma gratuita simulações interativas de matemática, química, biologia, física e ciências (phet.colorado.edu/ptbr/UniversityofColorado). A figura 1 mostra a interface do portal PhET - Interative Simulation mostrando alguns dos aplicativos disponíveis.

Figura 1: Interface portal PhET

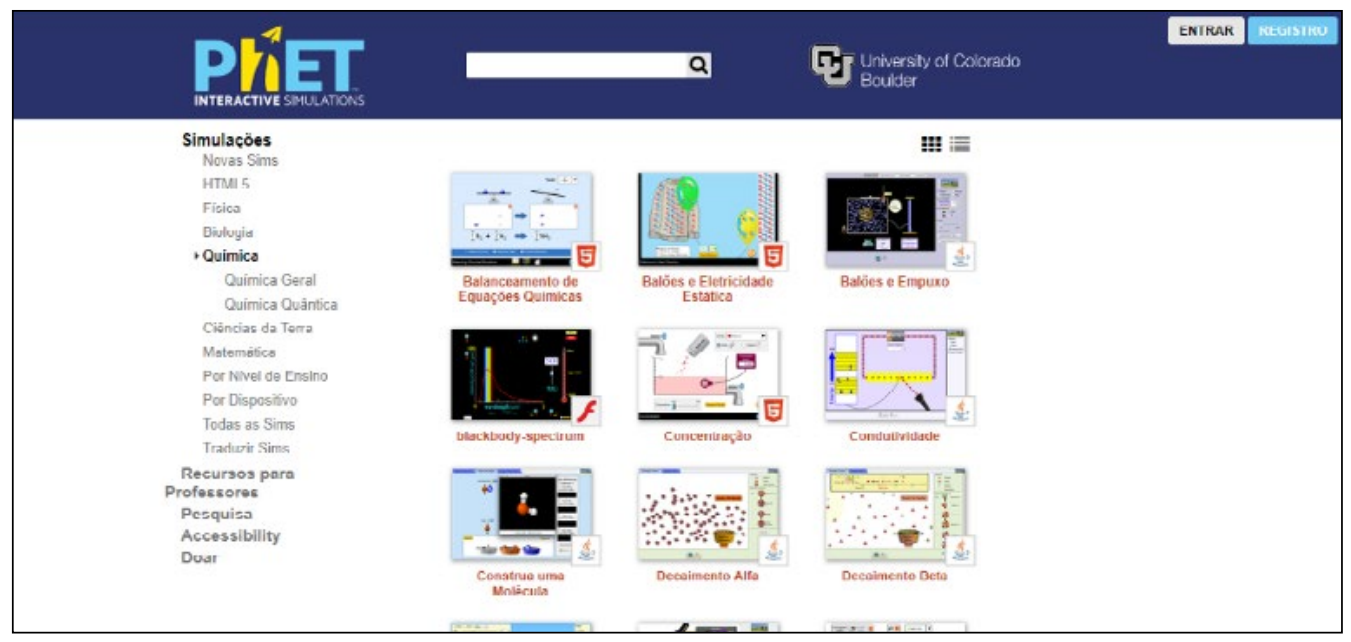

Fonte: Dos autores, 2019. 
Entre os aplicativos, disponíveis no repositório, como mostrado na figura 1, o objeto molecular selecionado para compor a atividade de ensino foi o "Construa uma Molécula", que traz alguns objetivos de aprendizagem, a saber: a) construír e visualizar moléculas em 3D. b) Descrever diferenças entre átomo e molécula. c) Construir moléculas simples a partir de átomos. d) Reconhecer que o índice numa fórmula molecular indica o número de átomos na molécula. e) Reconhecer que o coeficiente indica o número total de moléculas. f) Associar nome de moléculas comuns a múltiplas representações (PHET).

O segundo objeto molecular manuseável com esferas para representação atômicas e varetas para formar as ligações é constituído de material polimérico (Atomlig 77 Educação) figura 2, desenvolvido para construir modelos de estruturas moleculares de compostos inorgânicos e orgânicos incluindo: ácidos, aminoácidos, açúcares, carboxilas, fosfatos, hidrocarbonetos entre outras moléculas.

Figura 02: Atomlig 77 Educação.

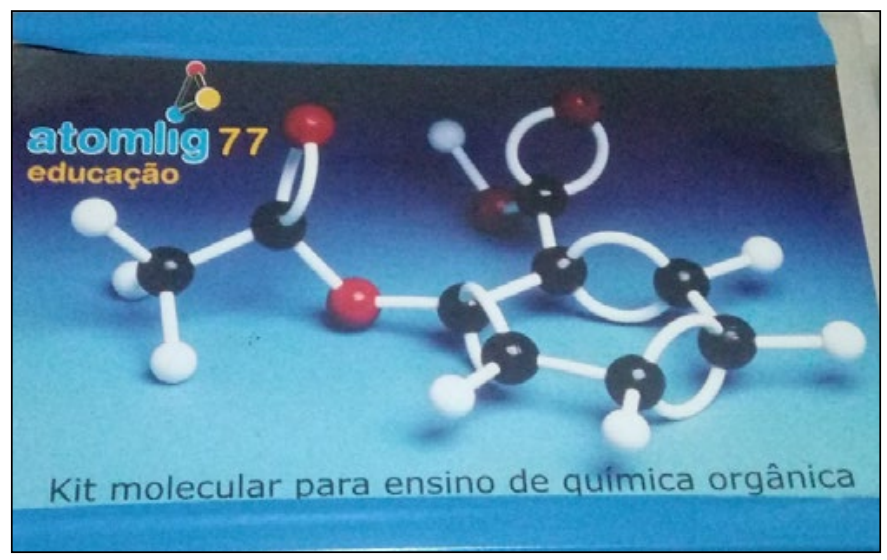

Fonte: Dos autores, 2019.

Em linhas gerais, o objeto molecular (figura 2), pode ser usado no ensino de diversos conceitos da Química, tais como: estereoquímica, análise conformacionais, propriedades físicas e químicas dos compostos acerca de suas estruturas moleculares e afins.

Para dar seguimento as ações, foi realizada uma atividade na perspectiva de que os alunos pudessem explorar os recursos para construção das estruturas moleculares orgânicas. Os participantes receberam o material que continha 6 kits $^{5}$ (Atomlig 77 Educação) com átomos (representados por esferas coloridas) para a construção das cadeias carbônicas e em outro momento tiveram acesso ao aplicativo "construa uma molécula" no portal PhET - Interative Simulation que

5 Conjunto de peças para montagem das estruturas moleculares sugeridas. Tanto no ambiente virtual quanto no material manuseável esferas de diferentes cores e tamanhos representavam os átomos usados para construção das cadeias carbônicas. 
dispunha diversos kits para construção de moléculas de modo virtual. Juntamente as resoluções por escrito, foi solicitado aos participantes que desenvolvessem atividades de construção, manipulação e visualização tridimensional do arranjo inter-atômico das estruturas moleculares, tanto virtual como usando o Atomlig 77 Educação. As estruturas orgânicas propostas para atividade pertenciam ao assunto funções orgânicas, sendo fornecido sua respectiva nomenclatura ou fórmula molecular conforme o Quadro 01:

Quadro 1: Estruturas Orgânicas Propostas

\begin{tabular}{|l|c|c|c|c|c|c|}
\hline \multicolumn{1}{|c|}{$\begin{array}{c}\text { Recurso } \\
\text { Pedagógico }\end{array}$} & \multicolumn{7}{|c|}{ Fórmula Estrutural } \\
\hline $\begin{array}{c}\text { Software PhET } \\
\text { - Interative } \\
\text { Simulation }\end{array}$ & $\begin{array}{c}\text { Kit 1 } \\
C_{3} H_{8}\end{array}$ & $\begin{array}{c}\text { Kit 2 } \\
\text { Isobutano } \\
\text { ou Metil- } \\
\text { Propano }\end{array}$ & $\begin{array}{c}\text { Kit 3 } \\
\text { 1,3dicloroeteno }\end{array}$ & $\begin{array}{c}\text { Kit 4 } \\
\text { Etino }\end{array}$ & $\begin{array}{c}\text { Kit 5 } \\
\text { Etanol }\end{array}$ & $\begin{array}{c}\text { Kit6 } \\
\text { Isopropillamina } \\
\text { ou 2-Metilpro- } \\
\text { panamina }\end{array}$ \\
\hline $\begin{array}{l}\text { Modelo } \\
\text { Molecular } \\
\text { Manuseável } \\
\text { Atomlig 77 }\end{array}$ & kit 1 & kit 2 & kit 3 & kit 4 & kit 5 & Kit6 \\
Eteno & Metanol & $\begin{array}{c}\text { Ácido } \\
\text { Metanoico }\end{array}$ & $\mathrm{CH}_{5} \mathrm{~N}$ & $\begin{array}{c}\text { Propanona } \\
\end{array}$ \\
\hline
\end{tabular}

Fonte: Dos autores, 2019.

Tal qual os objetos moleculares virtuais, o manipulável (Atomlig 77 Educaşão) estiveram à disposição dos alunos individualmente para que desenvolvessem a construção das estruturas carbônicas das moléculas listadas no Quadro 1. Durante as atividades, realizadas no laboratório de informática da escola, caso necessário, os alunos poderiam contar com o professor que atuou como mediador nos momentos de dúvidas referentes aos procedimentos operacionais dos objetos.

\section{RESULTADOS E DISCUSSÓES}

Nesta seção, são apresentados os apontamentos emergidos das atividades práticas desenvolvidas em diferentes situações de ensino, com enfoque na construção de cadeias carbônicas usando o kit Atomlig 77 Educação e o aplicativo "construa uma molécula" do portal PhET - Interative Simulation.

Nesse contexto, tomando como base a metodologia adotada, foi oportunizado aos alunos a realização de atividades práticas, admitindo que interagissem e avaliassem as potencialidades e limitações dos dois objetos de aprendizagem nas atividades oferecidas em dois ambientes de aprendizagem. Posteriormente, foi realizado o aprofundamento da análise, dos dados produzidos, a fim de identificar as potencialidades, bem como perceber e discutir as limitações apontadas pelos alunos ao avaliarem os recursos didáticos utilizados. 
Inicialmente, os resultados do questionário aplicado aos alunos e as observações participantes, descrevem, dentre outros apontamentos, se houve interação dos alunos com aplicativo "Construa uma molécula" e com kit molecular construtor de moléculas manuseável Atomlig 77 Educação; se contribuiu para a compreensão sobre cadeias carbônicas, fórmula estrutural e molecular; quais os pontos negativos em relação a esses recursos; a opinião dos alunos sobre o uso das tecnologias digitais na resolução das atividades; as opiniões quanto aos aspectos operacionais relacionados ao aplicativo.

Em relação a interface do aplicativo, os participantes, demostraram familiaridade e domínio com construtor de moléculas virtual, o que contribui para o desenvolvimento das atividades. Quando solicitados que avaliassem as funcionalidades do aplicativo "Construa uma molécula", os resultados mostram que a maioria absoluta classificou como "ótimo", (Quadro 2). Vale ressaltar que esses apontamentos convergem com as dimensões operacionais do aplicativo, onde cada um observa e interage individualmente conforme o seu ritmo.

Quadro 2: Questionário com os alunos quanto a funcionalidade do aplicativo.

\begin{tabular}{|c|c|c|c|c|}
\hline \multicolumn{5}{|c|}{ Quanto às funcionalidades do aplicativo - PhET construtor de moléculas, como você } \\
avalia?
\end{tabular}

Fonte: Dos autores, 2019.

O número de indicações no conceito ótimo, sugerem que o aplicativo atende a exigência desse requisito. Neste ponto, considera-se, funcionalidade como um comportamento ou uma ação para a qual possa ser utilizado com início e um fim, ou seja, algo passível de execução. Analisando os dados acima, identifica-se que o aplicativo foi explorado pelos alunos e que buscaram construir as cadeias carbônicas, interagindo com os recursos e fazendo representações submicroscópicas atômicomoleculares com aplicativo o que, provavelmente, contribuiu para o fortalecimento do pensamento químico, considerando o roteiro prático seguido. Segundo Giordan (2008) as contribuições desta sequência de ações de ensino estão em "ampliar seu conceito de molécula, estabelecendo novas generalizações a partir de conceitos de composição, geometria e movimento" (GIORDAN, 2008, p. 168).

A interface do aplicativo disponível na figura 3, monstra alguns dos aspectos desse aplicativo no quesito operacional e de acesso para o aluno durante a atividade. 
Figura 3: Interface do aplicativo Construa uma Molécula - PhET Interative Simulation.

(A) Construindo a molécula

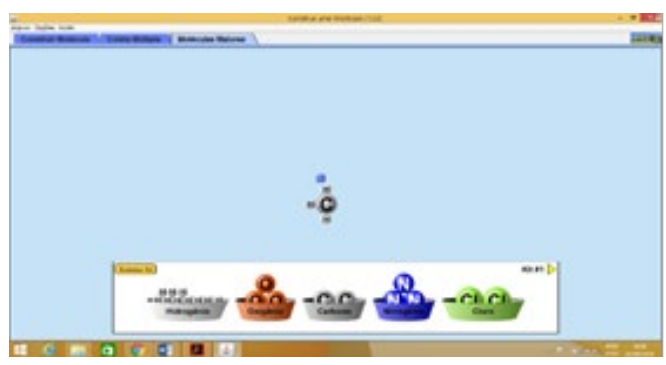

Fonte: Dos autores, 2019.
(B) Visualização tridimensional da molécula

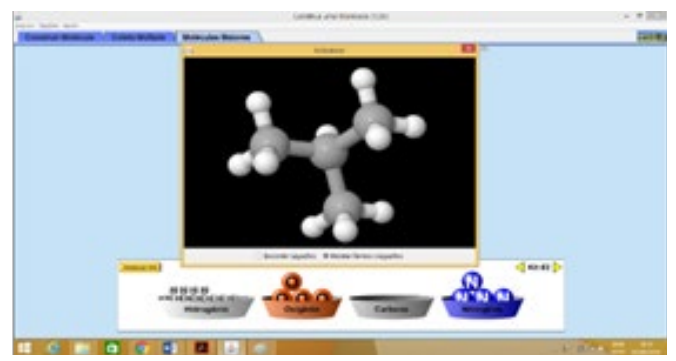

A imagem apresentada na figura 3A mostra o momento que os alunos estão construindo as estruturas moleculares solicitadas. Pode-se visualizar os átomos dos elementos químicos, na parte inferior da tela, disponíveis para serem arrastados até o centro da tela onde formam ligações para formarem as estruturas. Ainda na figura $3 \mathrm{~A}$, a tela de apresentação do aplicativo, mostra os modelos de cada elemento químico expostos de forma ilustrativa sendo-lhe atribuídas, a cada um, diferentes cores. Os modelos atômicos de cada elemento permanecem disponíveis individualmente, à disposição do aluno, para que possa clicar e arrastar o átomo que lhe convier ao centro da tela, e assim iniciar a construção da molécula. $\mathrm{Na}$ figura 3B, é possível visualizar no formato tridimensional uma das estruturas construída pelos alunos.

Quanto ao questionamento sobre o uso do aplicativo "construa uma molécula", buscou-se conhecer a opinião dos alunos sobre o uso dessa TD a partir da resolução das atividades. Segundo Paula (2015), as tecnologias digitais permitem a construção de aplicativos que criam, no computador, simulações virtuais análogas a situações reais eliminando as questões ligadas a segurança ou a recursos inalcançáveis. Com objetos moleculares virtuais, os alunos conduzem as simulações e são instigados a interpretarem seus resultados. $\mathrm{O}$ referido aspecto interativo expõe possibilidades de utilização desses recursos em diversos conceitos químicos tornando os alunos sujeitos de sua própria aprendizagem. A esse respeito os alunos argumentam que:

A4 - "O aprendizado fica mais dinâmico, onde é possivel ampliar o conbecimento na área da química de forma mais atrativa”. (Questionário: 28-05-18).

A5 - "[...] dessa forma podemos compreender de forma mais dinâmica e eficaz a construção de cadeias carbônicas". (Questionário: 28-05-18).

Entre as indicações que marcam a experiência vivenciada, identifica-se nos relatos dos alunos a palavra "dinamismo" e a frase "forma mais atrativa", além disso, mencionam, a eficácia na construção das cadeias carbônicas solicitadas. Tais apontamentos convergem com as concepções de Leite (2016), ao afirmar 
que, utilizar tecnologias digitais pode-se promover o interesse dos alunos pelos conteúdos, pois estão utilizando linguagens que fazem parte do universo conectado e interativos muito aceito pelos alunos. É concebível que abordagem de conceitos químicos, utilizando diferentes tecnologias, causem impacto nos processos de ensino e de aprendizagem, pois o foco pedagógico das ações desenvolvidas na presente atividade de ensino, focou no uso desse recurso digital e a participação ativa dos alunos.

Quando questionados sobre as possibilidades de ampliar os conhecimentos, ou seja, se com o auxílio do aplicativo houve contribuições para compreensão de conceitos relacionados as cadeias carbônicas, os alunos fizeram os seguintes relatos:

A2 - "[...] sim, pois quando utilizamos o software vemos de outra forma é uma maneira mais fácil de se compreender". (Questionário: 28-05-18).

A4 - "[...] Sim, pois a partir do software, pode-se compreender a estrutura 3D, bem como criar diversas ou inúmeras moléculas”. (Questionário: 28-05-18).

A5 - "Sim, pois a tecnologia do software traz uma melhor visualização das moléculas realizadas”. (Questionário: 28-05-18).

Os excertos mencionados expõem uma avaliação positiva por parte dos alunos quando se busca representar, visualizar e compreender as formas estruturais das moléculas. O aluno A2, ao relatar que com o aplicativo "vemos de outra forma" e que possibilita a compreensão, confirma, as expectativas atribuídas ao aplicativo "Construa uma molécula". Nesse sentido Maciel e Backers (2013, p.161), afirmam que "[...] criar espaços de aprendizagem, é buscar alternativas para que, dentro ou fora da sala de aula, os alunos tenham espaços de interação, colaboração e aprendizagem". Pode-se observar na afirmação do aluno A4, possibilidades trazidas no quesito visualização das estruturas moleculares, porém vale destacar que "ao permanecer na representação tridimensional, pode-se correr o risco de estagnar sua capacidade de elaborar outras formas de representação" (GIORDAN, 2008, p.193). Nesse ponto, estão entre as limitações, tomar como absoluto um único método ou recurso pedagógico, ainda que no espaço virtual. É desejável estabelecer um equilíbrio entre métodos de ensino, recursos didáticos e revisões teóricas, ou seja, conforme a situação problema o aluno poderá alterar a modalidade de simulação para outros modelos representativos, revisitar a literatura e perceber o conceito de cadeia carbônica, representado em diferentes formas (GIORDAM, 2008).

Em relação as dificuldades quanto ao uso do objeto molecular virtual "Construa uma molécula", percebe-se não ter havido. Além disso, nas anotações de campo, foram registradas a participação ativas dos alunos no desenvolvimento das atividades e os resultados foram positivos quando questionados se o aplicativo havia auxiliado na compreensão da formação e representação das cadeias carbônicas.

Esse suporte ao aprendizado provido pelas tecnologias digitais parece ser particularmente útil para representar modelos moleculares, e essas constatações tendem a crescer, uma vez que a tecnologia digital, já se faz presente em boa parte das ações desempenhadas pelos jovens (KENSKI, 2007). Assim, diante dos relatos, 
também é notada a importância desse objeto molecular no quesito visualização e representações de modelos moleculares tridimensionais. No entanto, para esta estratégia pedagógica sugere-se que o docente atue como um mediador entre o aluno, os aspectos conceituais e a tecnologia usada.

Além do aplicativo "Construa uma molécula" no âmbito virtual, utilizouse o Atomlig 77 Educação manuseável, sendo este, outro objeto molecular, para o desenvolvimento das atividades, ou seja, estratégia pedagógica, que também permitiu a interação dos alunos. Nessa conjuntura, analisou-se as potencialidades e as limitações apontadas pelos alunos em relação a este construtor de moléculas (cadeias carbônicas), no contexto da atividade.

Atentos para que houvesse a participação ativas dos alunos, buscouse contemplar a dinâmica baseada na interatividade e autoria na construção das moléculas, provocando questionamentos correlatos ao reconhecimento das estruturas a serem montadas. Vale lembrar que as atividades propostas visavam incentivar o aluno a refletir, agir e transitar por conceitos fundamentais da química, buscando estreitar relações entre aluno e os conteúdos.

Desse modo, questionou-se, se houvera pontos positivos, a partir das experiências vivenciadas nas atividades, mediadas pelo kit molecular "Atomlig 77 Educação". Os apontamentos realizados pelos alunos indicam que sim, como os relatos apresentados, a saber:

A2 - "Sim houve pontos positivos, pois me favoreceu um maior conbecimento em relação ao conteúdo estudado"

A4 - "O kit, além de trazer conhecimento ao aluno, ainda serve de diversão e desafio, ao mostrar as moléculas, pois assim o aluno aprende brincando".

A6 - "[...] estamos cansados de aulas teóricas, necessitamos de práticas como "atomlig" para compreensão da matéria de forma divertida e entusiasmante".

A1 - "Pois traz uma melhor visualização da molécula e facilita o entendimento. "

Nesses excertos, observa-se que ao utilizar o Atomlig 77 Educação como modelos representativos para estruturas orgânicas, reforçou a ideia de um recurso pedagógico mediador capaz de proporcionar a autoria, dos alunos nas representações de cadeias carbônicas, configurando com um parceiro nos processos de ensino e de aprendizagem de cadeias carbônicas. A presença do lúdico manifestado nos relatos: "aprende brincando", "divertida e entusiasmante" corroboram com Kiel e Crisostimo (2017), ao confirmarem a influência do lúdico no ensino, bem como a aproximação dos alunos ao conhecimento científico. Para Soares (2004), o manuseio é uma interação muito positiva, sua importância parte do lúdico ao conhecimento, implícito no material. A interação física e motora, quando a pessoa opera e manuseia um brinquedo, um simulador ou participa de uma atividade lúdica, admite uma correspondência intelectual (SOARES, 2004).

A interação associada ao lúdico são aspectos que podem contribuir para a expressiva aceitação desse construtor molecular. No entanto, entre as principais 
características desse objeto de ensino, é que, se estabelece o contato direto com os alunos através do manuseio. Sendo assim, pode-se observar que ao utilizar esse recurso como modelo para formação e representação de estruturas moleculares, associadas aquelas visualizadas no aplicativo "Construa uma molécula", foram ampliadas as possibilidades da construção do conhecimento pelo aluno.

Nesta perspectiva, os resultados do presente estudo corroboram com Lima (2015), quando ressalta que o Atomlig 77 Educação como um potencial recurso para alunos de química orgânica, pois ele permite que estruturas moleculares complexas sejam construídas e estudadas de forma concreta e palpável. Muito embora, esse objeto molecular seja composto de material polimérico, apresenta as esferas perfuradas de cores diferentes e varetas que simulam as ligações químicas, ele pode estar conjugado a outros recursos, inclusive virtuais nas mais diferentes situações de ensino. Nesse sentido, entende-se que a decisão deve partir do professor, sobre a inserção desses recursos na prática pedagógica, considerando: o objetivo desejado na atividade de ensino, às estratégias a serem utilizadas, o grau de profundidade e competências que se espera que os alunos alcancem (RIBEIRO et al. 2016).

Contudo, é importante mencionar que o Atomlig 77 Educaşão não traz somente possibilidades, mas também pode apresentar limitações. Uma limitação apontada pelos alunos foi o número de ligações, onde alguns átomos (representados por esferas) apresentam perfurações adicionais. Essas perfurações, apresentadas nas esferas em sua maioria não correspondem ao número de ligações (valências) equivalentes as configurações eletrônicas dos átomos dos elementos que representam. Tal como no átomo de oxigênio, representado por uma esfera de cor vermelha que deveria ter apenas duas perfurações, entretanto apresenta quatro. Embora apontado como ponto negativo, esta limitação não comprometeu o desenvolvimento das atividades com os alunos.

Com base na experiência vivenciada com o construtor molecular Atomlig 77 Educação quando solicitado aos participantes que apontassem os pontos negativos ou desconformidades em relação ao seu manuseio e ilustração, esse caso relacionado as perfurações, foi exposto pelos alunos:

\section{A1 - "os buracos não vêm de acordo com a ligação"}

Entre os relatos sobre as inconsistências do material "Atomlig 77 Educação" descritos, $50 \%$ se referiram as perfurações superiores a valência (número de ligação possíveis) do átomo, o que pode dificultar a organização estrutural. No excerto anterior o aluno A1 relata "os buracos" fazendo referência as perfurações necessárias para o encaixe das varetas que representam as ligações.

A2 - [..]" deveriam ter suas respectivas ligações, pois não são tetravalentes iguais ao carbono".

Os relatos descritos fazem referência aos demais elementos químicos presentes no Atomlig 77 Educação e suas respectivas ligações. Ainda sobre limitações identificadas nas esferas utilizadas, os alunos questionaram o diâmetro das esferas (figura 2) utilizadas nas representações dos átomos, dado que, com exceção do 
hidrogênio todas as esferas apresentam o mesmo diâmetro. Para tanto, ao que parece tais constatações vêm ao encontro das concepções de Giordan (2013), quando defende que "nessa fase de transição pode-se operar por outra modalidade de simulação, capaz de incorporar outros modelos representativos das estruturas moleculares, por exemplo, a simulação computacional" (GIORDAN 2013 p. 193).

Mesmo diante das desconformidades estruturais identificadas no atomilig 77 Educação, os dados sugerem que é importante a junção das duas modalidades de modelos moleculares, uma vez que estimulam os alunos a reconhecerem as legitimidades conceituais na construção das estruturas moleculares e os levam a representações diversificadas.

Figuras 4 : "Objeto molecular" Atomlig 77 Educacional”

(A) Esferas e bastões

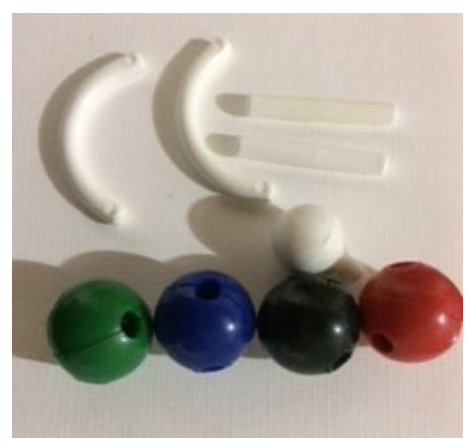

(B) Modelo estrutural

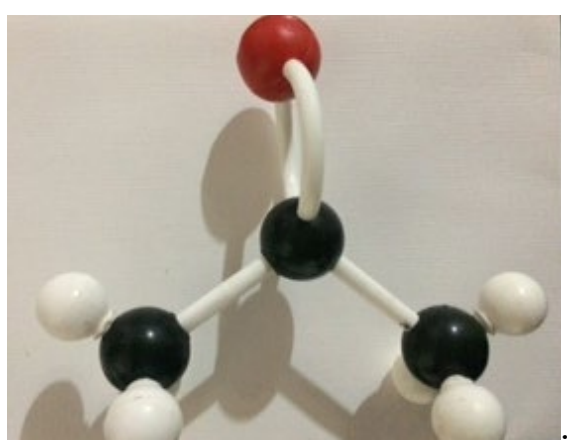

Fonte: Dos autores, 2019.

A imagem apresentada, na figura 4A mostra os objetos (esferas e bastões) que são utilizados na construção das estruturas moleculares solicitadas. Observase, esteticamente, os modelos de átomos de colorações diferente para cada elemento químico, além das perfurações que são usadas para conectar os átomos representando a formação das ligações químicas. $\mathrm{Na}$ figura 4B é possível visualizar, uma das estruturas construída pelos alunos, que foi a estrutura da propanona.

Ao final das atividades desenvolvidas, consideradas como suporte ao aprendizado de conteúdos de Química Orgânica (estruturas moleculares), pode-se perceber que as tecnologias utilizadas se mostraram aceitáveis e sugestivas para o ensino de cadeias carbônicas. Além disso, o uso das tecnologias digitais em prática pedagógicas, se bem estruturadas ao objetivo do professor, poderão acompanhar outras tecnologias não digitais com características experimentais, mediante planejamento das ações a serem executadas pelo docente.

Nesse caso, quando não se dispõe do Atomlig 77 Educação, entende-se que esses modelos moleculares também podem ser substituídos por materiais alternativos, por exemplo: papel, palitos de madeira, bolas de isopor ou plástico, porém estas tecnologias não digitais com características experimentais geralmente 
são em pouca quantidade, o que pode limitar seu uso à representação de moléculas pequenas (GIORDAN; GÓIS, 2004; GIORDAN, 2013).

Diferentes aspectos ilustrativos e interativos utilizados na representação de conceitos devem ser expostos aos alunos para não se limitarem a capacidade de elaborar outras formas de representação. Ao que parece, os recursos didáticos que compuseram essa estratégia pedagógica, se destacaram em meio às percepções dos alunos como uma alternativa capaz de contribuir no sentido de estreitar relações com os conteúdos apresentados de forma teórica. Estas concepções extraídas dos relatos dos alunos reforçam a argumentação de Kenski (2009), quando enfatiza a participação de alunos na construção e reconstrução de saberes científicos de forma interativa, tornando-os participantes ativos no processo de ensino.

Por fim, é importante salientar as potencialidades que são oferecidas por estratégias pedagógicas em que se utiliza tecnologias digitais a fim de possibilitar a interação do aluno com os conceitos químicos. O envolvimento ativo dos alunos nas atividades, revelam possibilidades, fazendo com que progridam nos seus conhecimentos intuitivos aos científicos. Desse modo, em notas de campo registrou-se posicionamentos positivos referentes as percepções dos alunos frente aos questionamentos relacionados a experiência vivenciada. Esses movimentos corroboram para a implementações de ações pedagógicas inovadoras que podem aproximar os alunos dos conceitos químicos de forma interativa ampliando as possibilidades nos processos de ensino e aprendizagem.

\section{CONSIDERAÇÓES FINAIS}

Diante do conjunto de resultados analisados, considera-se as potencialidades e limitações dessas atividades de ensino, ao passo que permitiu emergir reflexões em direção aos processos de ensino e aprendizagem. Ao longo do desenvolvimento da pesquisa sugeriu-se aos participantes a utilização de forma conjunta os dois objetos moleculares. Com base na proposta mencionada, compreende-se que tanto o kit Atomlig 77 Educação, quanto o objeto molecular virtual construa uma molécula, trouxeram contribuições pedagógicas importantes para os estudos de cadeias carbônicas.

A presente pesquisa reforça o discurso da necessidade de práticas pedagógicas diversificadas que possam contribuir para aproximação de alunos frente aos conceitos químicos de forma interativa.

Em linhas gerais constatou-se que o tempo estimado para o desenvolvimento das atividades realizadas pelos alunos se mostrou satisfatório. Realizar as atividades práticas em diferentes espaços (digital e manuseável) possibilitou aos participantes, posicionamentos interativos e conectados, estando em sintonia ao dia a dia dos alunos.

Os resultados apresentados nesse artigo mostram que os diferentes modelos representativos de estruturas moleculares orgânicas (cadeia carbônica) sejam no campo virtual ou em modalidade de representação palpável, não devem se 
substituírem, mas sim se complementarem, visto que podem motivar os alunos e aprimoram as representações de cadeias carbônicas. Nesta perspectiva, as duas tecnologias utilizadas, permitiram a participação ativa e dinâmica dos alunos. Todavia, considera-se importante o aperfeiçoamento na mediação dessas práticas, nas quais, entende-se ser substanciais complementos aos conteúdos teóricos nos processos de ensino e aprendizagem da química.

Por fim, pode-se observar que os objetos moleculares, podem desempenhar um papel importante para representações de atômicos e moléculas. Acrescenta-se ainda, na sugestão para o professor inserir como estratégia de ensino, aquela que contemple ao máximo seus objetivos, que esteja ao seu alcance, sobretudo a que mais desperte o interesse por parte dos alunos, superando possíveis limitações.

\section{REFERÊNCIAS}

ALMEIDA, A. C.; SILVA, N. C.; CARVALHO, Q. C. Utilização de Modelos Moleculares Versáteis de Baixo Custo na Representação Tridimensional das Cadeias Carbônicas. Encontro nacional de ensino de química, v. 15, p. 2010, 2010.

ANJOS, A. M. Tecnologias da informação e comunicação, aprendizado eletrônico e ambientes virtuais de aprendizagem In: MACIEL, C. (Org.). Educação à distância. Ambientes virtuais: construindo significados. 2013. Disponível em: https://bit. ly/2kcR26F. Acesso em: 28 maio 2019.

ATOMLIG 77 EDUCAÇÃO - Disponível em://atomlig.com.br/educacao.htm. Acesso em: 03 jun. 2018.

GABINI, W. S.; DINIZ, S. R. E. A experiência de um grupo de professores envolvendo ensino de química e informática. Ensaio Pesquisa em Educação em Ciências, v. 9, n. 1, p. 9-17, 2009.

GIORDAN, M. Computadores e linguagens nas aulas de ciências: uma perspectiva sociocultural para compreender a construção de significados. Ijuí: Ed. Unijuí, 2013. $-328 \mathrm{p}$.

GIORDAN, M.; GÓIS, J. Telemática Educacional e Ensino de Química: considerações sobre um construtor de objetos moleculares. Revista Linhas Críticas, Brasília, v. 11, n. 21, p. 285-302, 2005. Disponível em: https://www.redalyc.org/pdf/1935/193517360008. pdf. Acesso em: 20 fev. 2019.

KENSKI, V. M. Educação e tecnologia: o novo ritmo da informação. Campinas, SP: Papirus, 2009.

KIEL, C. A.; CRISOSTIMO, A. L. O lúdico e o ensino de ciências: saberes do cotidiano. Guarapuava: Ed. Da Unicentro, 2017. 174p.

LEÃO, M. F.; SOUTO D. L. P. Objetos educacionais digitais para o ensino de física.

Revista Tecnologias na Educação, v. 7, n. 13, p. 1-12, 2015. Disponível em: http:// 
tecedu.pro.br/wp-content/uploads/2015/12/Art16-vol13-dez2015.pdf. Acesso em: 17 fev. 2019.

LEITE, S. B. Tecnologias no ensino de Química. Ed. Appris, Curitiba, PR, 2015.

LEVY, P. Cibercultura. 1. ed. São Paulo: Ed. 34, 1999.

LIMA, J. F. O USO DE MODELOS MOLECULARES NO ENSINO DE QUÍMICA ORGÂNICA. Itinerarius Reflectionis, v. 10, n. 2, 2014. Disponível em: https:/ /www. revistas.ufg.br/rir/article/view/26721. Acesso em: 10 mai. 2019.

MACIEL, C.; BACKES, E. M. Objetos de Aprendizagem, objetos educacionais, repositórios e critérios para a sua avaliação. 2013. In: MACIEL, C. (Org.). Educação à distância. Ambientes virtuais: construindo significados. 2013. Disponível em: https:/ / bit.ly/2kcR26F. Acesso em: 25 maio 2019.

MARTINS, I. P. Formação inicial de professores de física e química sobre a tecnologia e suas relações sócio-científicas. Revista Electrónica de Enseñanza de las Ciencias, v. 2, n. 3, p. 293-308, 2003.

OLIVEIRA, F. C.; SOUTO, D. L. P.; CARVALHO, J. W. P. Seleção e análise de aplicativos com potencial para o ensino de Química orgânica. Revista Tecnologias na Educação, v. 17, p. 1-12, 2017.

OLIVEIRA, M. M. Como fazer pesquisa qualitativa. 7. ed. Petrópolis: Vozes, 2016.

PAULA, H. F. As tecnologias de informação e comunicação, o ensino e a aprendizagem de ciências naturais. In: MATEUS, A. L. (Org.). Ensino de Química mediado pelas TICs. Belo Horizonte: Ed. da UFMG, 2015.

PAULETTI, F.; ROSA, M. P. A.; CATELLI, F. A importância da utilização de estratégias de ensino envolvendo os três níveis de representação da Química. Revista Brasileira de Ensino de Ciência e Tecnologia, v. 7, n. 3, 2014.

PHET. Interactive Simulations for Science and Math. Universidade de Colorado Boulder, 2019. Disponível em:https://phet.colorado.edu/pt_BR. Acesso em: 02 jun. 2019.

POZO, J. I.; CRESPO, M. Á. A aprendizagem e o ensino de Ciências. $5^{\text {a }}$. ed. Porto Alegre: ArtMed Editora, 2009. 286 p.

RIBEIRO, A. A.; GRECA, I. M. Simulações computacionais e ferramentas de modelização em educação química: uma revisão de literatura publicada. Química nova. Vol. 26, n. 4, p. 542-549, 2003. Disponível em: http://www.scielo.br/pdf/\%0D/qn/ v26n4/16437.pdf. Acesso em: 03 jul. 2019.

RIBEIRO, M. E. M. et al. Natureza Epistemológica dos Objetos de Aprendizagem para Ensino de Química no Ensino Médio. Revista de Ensino, Educação e Ciências Humanas, v. 17, n. 3, p. 245-250, 2016. 
SILVA, T. S.; SOUZA, J. J. N; FILHO, J. C. Construção de modelos moleculares com material alternativo e sua aplicação em aulas de química. Experiências em Ensino de Ciências V.12, N², p. 104-117, 2017.

SOARES, M. H. F. B. O lúdico em Química: jogos e atividades aplicados ao ensino de Química. UFSCar, 2004. Disponível em: https://repositorio.ufscar.br/handle/ ufscar/6215. Acesso em: 28 jun. 2019.

SOUTO, D. L. P. Transformações expansivas na produção da matemática online. 1 ed. - São Paulo: Cultura Acadêmica, 2014.

TAROUCO, L. M. R.; SANTOS, P. M.; ÁVILA, B.; GRANDO, A; ABREU, C. S. Multimídia Interativa: Princípios e Ferramentas. Renote - Revista Novas tecnologias em Educação, v.7, n. 1, p. 1-9, 2009. 